\title{
THE ROLE OF RURAL HETEROGENEITY IN KNOWLEDGE MOBILISATION AND SOCIOTECHNICAL TRANSITIONS: REFLECTIONS FROM A STUDY ON ELECTRIC VEHICLES AS AN ALTERNATIVE TECHNOLOGY FOR CORNWALL, UK
}

\author{
Shukru Esmene ${ }^{1}$, Michael Leyshon ${ }^{2}$
}

Received 26 February 2019, Revised 25 November 2019, Accepted 2 December 2019

\begin{abstract}
Mobilising knowledges across a geography creates opportunities for transitions to smart systems. Publics in a geography are consequently able to form their perspectives around a system and align potential benefits with their needs. Intelligent transport systems are an example of smart living and EVs are cited as an alternative technology that are key to their application. This conceptual paper uses EVs as an example to demonstrate how knowledge mobilisation relating to such technologies can better cater to a geography's needs. Unfortunately, current EV studies focus on a rural-urban binary. Thus, this conceptual contribution reflects on a study in Cornwall, UK, to reveal the heterogeneous influences on rural EV-related perspectives. This heterogeneity manifests both in particular locations and across cases. Overall a suite of transferrable participatory methods to improve rural knowledge mobilisation is outlined.
\end{abstract}

Key words: Sociotechnical transitions, Knowledge mobilisation, Intelligent transport systems, Electric vehicles, Smart systems

\section{Introduction}

The adoption of alternative technologies plays an integral role in transitions towards intelligent transport systems. The core aim of these transitions is to ensure that the transport options available across a specific geographical area are best suited to the travel needs of the resident population (Docherty et al. 2018). The better alignment of supply and demand with a population's needs increases the efficiency of a transport system. In this regard, efficiency is considered holistically and can include reducing environmental impacts, managing fuel and energy demand,

\footnotetext{
${ }^{1}$ Dr Shukru Esmene, PhD., University of Exeter, European Centre for the Environment and Human Health, Knowledge Spa, RCH Cornwall, Truro, Cornwall, TR1 3HD, United Kingdom, ORCID: 0000-0001-8561-6055, e-mail: s.esmene@exeter.ac.uk

2 Dr Michael Leyshon, PhD., University of Exeter, Centre for Geography and Environmental Science, College of Life and Environmental Sciences, Peter Lanyon Building, Penryn Campus, Treliever Road, Penryn, Cornwall, TR10 9FE, Cornwall, United Kingdom: ORCID: 0000-0001-9411-6167, e-mail: m.leyshon@exeter.ac.uk
} 
and enabling the provision of route, time and cost optimising transportation solutions (Poggi et al. 2017). However, recognising that efficiency has a variety of definitions can create ambiguity, particularly, when presenting alternative transport solutions to specific publics (Wolf and Moser, 2011; Wynne, 1992). Hence, the framing of an alternative technology's purpose, opportunities and challenges, including its potential improvements to a system's efficiency, is dependent upon context (Holland et al. 2016). This paper moves beyond the rural-urban binary currently dominating discourses around electric vehicles (EVs). By doing so, the importance of context in mobilising knowledges relating to intelligent transport systems and their implementation in countryside locations is highlighted.

The overall aim of this commentary piece is to demonstrate how understanding both the specific context as well as the heterogeneity of a rural region is key to any transition involving an alternative technology. This is particularly relevant to defining the alternative technology's efficiency in relation to an existing system (such as regional transport systems) and ensuring the public in the specific region are knowledgeable in regard to the alternative technology that is introduced. Moreover, the paper details how each component of a transition towards intelligent systems is received and perceived differently according to geographical contexts. For instance, the renewable energy infrastructure, potentially to enable a clean energy transition for EV use, will interrelate with rural geographies and publics differently compared to EVs themselves (Cotton and Devine-Wright, 2012). This paper highlights two levels of complexity; i) the heterogeneity of rurality itself and ii) the multiplicity of an intelligent transport system and the variance in how each component of a system can influence a region. The conceptual approach to address this complexity is developed through a critical overview of current research relating to rurality and EVs, and reflections from an in-depth qualitative study conducted in Cornwall, United Kingdom (UK). The case study is presented in more detail in the paper's 'Methods' section. The critical reflections on this case and its implications for the future of rural transitions to intelligent transport systems are covered in the two sections, 'Results and Discussion' and 'Conclusions', that follow the 'Methods' section.

\section{Theoretical Background}

Technological transitions are significantly shaped by the knowledges available to the key actors who will potentially be influenced by an alternative technology. The increased availability of clear and relevant knowledges better enable the provision of such transitions (Docherty, 2018; Latour and Weibel, 2005). Thus, technological transitions are characterised by key actors acting on the relevant knowledges available to them and creating new knowledges through the application of an alternative technology within their context (Docherty, 2018; Latour and Weibel, 2005). Yet, knowledge availability is not exclusive in enabling smoother transitions. Schot et al (2016) suggest public perceptions constructed around a specific technology may prove to be more significant in stimulating the successes or failings of a transition. Perceptions constructed by key actors, including publics, policy makers, the media and industry, determine the momentum of a transition (Ryghaug et al. 2012; Tiessen et al. 2008).

EVs are often cited as an important component of a technological transition towards establishing effective intelligent transport systems (Mathieson et al. 2016). However, the academic literature regarding geographic specific perceptions around EVs remains an underdeveloped field, with a focus primarily on: (i) technical EV issues; (ii) narrow consumer-oriented perspectives; and (iii) the use of EVs in urban areas with rural comparisons made under a binary lens, i.e. not engaging with the variance between rural contexts. The majority of academic studies focus predominantly on technical aspects of EV development and uptake; battery composition, range of EV batteries, battery lifetime, and EV integration into energy systems are seen as the main challenges of widespread EV implementation (Barre et al. 2014; Ugle et al. 2013; Zhang et al. 2013; Ji et al. 2012). The focus on technical development by academe, led by the physical sciences, limits the mobility of EV- related knowledges to specific academic disciplines and publics that have niche interests in technical knowledges. Consequently inhibiting their infiltration into wider society (Wynne, 2005), and constraining the epistemological diversity of the knowledges generated. Epistemological diversity can aid communication by allowing knowledges to cater to a wider range of contexts and the actors within those contexts (Barr, 2011; Wynne, 2005). This is important in 
relation to the adoption of alternative technologies. In essence, knowledges relating to a technology and its potential improvement of an existing system can be made relevant to publics and regions more explicitly (Hermwille, 2016).

A wide network of engagement and openness relating to the context specific influences of a technology can be achieved in an area when knowledges are generated and mobilised through multi-actor scenarios (Brulle et al. 2012; Latour and Weibel 2005). The multi-actor approach to mobilising knowledges takes into consideration socio-demographic, cultural and geographical nuances. Unfortunately, there is limited evidence of such multi-actor approaches within the existing research on EV-related knowledges. Social science contributions to EV research are largely restricted to consumer-oriented perspectives (Peters and Dutschke, 2014; Axsen and Kurani, 2012), and are therefore narrow in both audience and geographical scope (Bunce et al. 2014). Such consumer-oriented research tends to focus on functionality and cost related knowledges, comparing consumer perceptions of EVs with that of market-dominating petrol and/or diesel vehicles, and highlight EV price as a major barrier to knowledge mobilisation (Larson et al. 2014; Wu et al. 2014; Egbue and Long, 2012). These consumer and product based insights present knowledges in a generalised manner. Place dependent variability is, at best, addressed across rigid definitions of rurality and urbanity (Newman et al. 2014). This poses problems to actuating an alternative technology transition. Such transitions require effective mechanisms of knowledge mobilisation. In turn, this necessitates a detailed understanding and interpretation of the nuances of place, i.e. understanding the culture, socio-demographics and geography of a defined region, if they are to influence an existing system's positively (Chilvers and Longhurst, 2016). Current research in this area needs to be enhanced by exploring the variance and heterogeneity of rurality and urbanity in relation to transport technologies. The next section of this paper outlines how a detailed rural case study has been used to address this heterogeneity from a rural perspective.

\section{Methodology}

EVs are currently the most widely available alternative to petrol / diesel vehicles and provide an appropriate case to explore how the contextual characteristics of a particular place and its publics may influence the impact of EVs on an existing transport system. Additionally, using EVs as a case study can reveal how knowledges relevant to their impact can be effectively mobilised. Thus, understanding the complex conditions presented by such a case calls for the adoption of a reflexive praxis (Chilvers et al. 2013). This research is informed by a reflexive approach to critically engage with the rich data generated via a range of qualitative methods. These are outlined below.

Reflexive practice situates direct experiences from field research within emerging scholarly literatures, in this case, sociotechnical transitions. The field study was conducted over a year and utilised a variety of in-depth qualitative methods. Reflexive field diaries were kept throughout the field work, including insights from informal and formal interactions with local industry, local government and key media actors and sources in the region. During the main empirical part of the study focus groups were held with publics in a rural case study location (this is described in more detail below), and purposive sampling helped to capture perspectives from a wide range of characteristics from the living age of a small town (where the populations were between 5,000 and 25,000 ) or a village (where the populations were below 5,000 individuals), to socio-economic status and educational attainment of residents. Furthermore, a series of interviews were held with academic researchers working on studies relating to the use of EVs (Esmene et al. 2017). All the data generated in the study was inductively coded (Elo and Kyngas, 2007), using qualitative data analysis software (NVIVO), to allow the rich data to form context-led insights into studied case.

Our case study location was Cornwall, UK which is a highly nuanced rural landscape. Cornwall's location in the UK can be seen in the map (Fig. 1) 


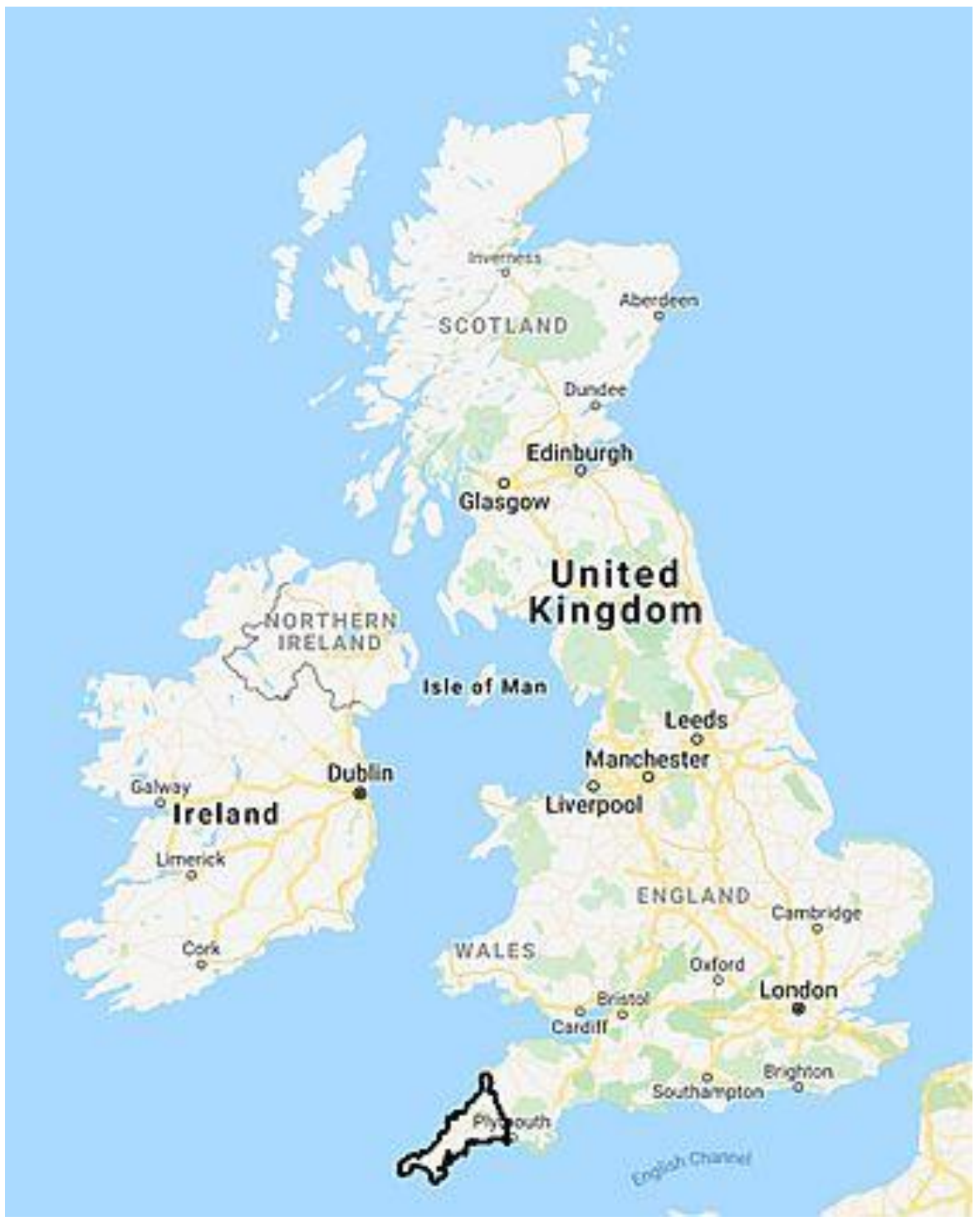

Fig 1. Cornwall's position within the United Kingdom (Cornwall Council, 2019).

The study location provides a strong exemplar of rural heterogeneity which has a significant influence on the inclusion of publics, as well their understanding of technological transitions. Cornwall, UK is predominately a rural county but does have ten settlements classified as small urban hubs (Fig. 2). These include Truro, a Cathedral City, and its largest population cluster, comprising of St. Austell, St Austell, St Austell Bay, Carlyon, St Blaise/Tywardreath and Par, which has an aggregated population of 34,700 (Office for National Statistics, 2011). Further, Cornwall has a relatively low population density (151 people per kilometre squared) compared to other counties in the UK, ranking 79th out of 90 counties (Office for National Statistics, 2012). Cornwall also offers an interesting geographical context in which to understand rural perceptions relating to EVs. It is the only mainland county that remains unconnected to the UK's motorway network (Gray et al. 2001) and Cornish roads have lower traffic counts compared to the rest of the UK; 1,446,952 cars were counted on Cornwall's roads in 2012 (Department for Transport, 2012). Even the neighbouring county of Devon, a relatively rural setting, had 2,569,118 cars on its roads in the same traffic count year (Department for Transport, 2012). Another important nuance to consider is that three roads (the A30, A390, and A39) account for over $60 \%$ of the overall traffic in the county of Cornwall (Department for Transport, 2012). Finally, Cornwall constitutes an interesting case study from a socio-demographic perspective as it has an increasingly ageing population (Cornwall Council, 2011), which according to Gamble et al. (2000) are less likely than young people, to be accepting of alternative technologies. 


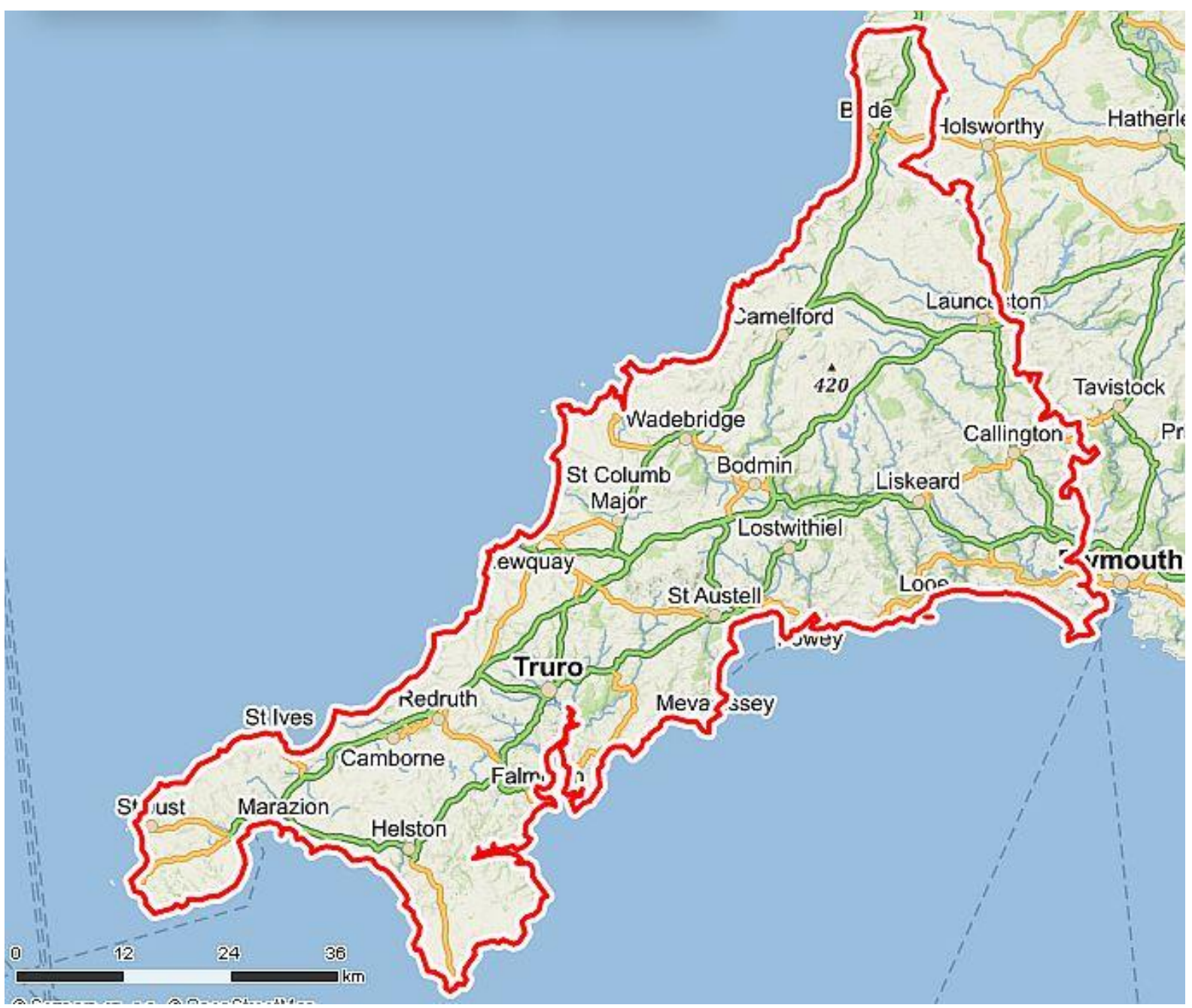

Fig 2. County of Cornwall. Source: mapy.cz

The heterogeneous geography of Cornwall is reflected upon below to illustrate how knowledge is mobilised during a sociotechnical transition and the effects this has on rural transport systems. These include potential impacts to air quality, how the technology aligns with the region's energy landscape and whether the EVs would be practically suitable for the lifestyles prevalent in Cornwall; including how key actors (publics, local government and industry perceive their suitability) perceive their suitability. Structuring the issue in this way exposes how the uniqueness within a rural setting regarding generalised discourses around rurality are the key drivers behind knowledge mobilisation and sociotechnical transitioning. The uniqueness of geography, culture, socio-demographics and local governance in Cornwall are explored in this paper to demonstrate a framework that can be used to understand the influences of rural heterogeneity from one case to another. Hence, the key influences discussed in the next section have implications for regional, national and international theory and practice.

\section{Discussion}

This paper does not present any empirical data due to its commentary format. However, the key reflections on the suite of qualitative, reflexive methods used during the in-depth case study are outlined here. The focus on consumerism in EV-related research addresses only a narrow segment of perspectives in their role as an intelligent transport system component. Nonetheless a population's purchase behaviour and prevalent opinions around a technology as a product are valuable insights in ensuring a scalable adoption of such technologies (Plotz et al. 2014). In rural contexts the prevalent opinions around consumer products tend to supersede their consumerist framing more so than in 'fast-paced' urban lifestyles where marketing and consumer messages are in close proximity, and constantly at the forefront of an interaction with a new product and/or 
technology (Jad'ud'ová et al. 2018; Siwach and Dahiya, 2009). Hence, condensing a technology such as the EV to a consumer product can veil the wider implications of the technology i.e. as a component of a technical transition and an intelligent transport system.

The extant literature on EVS highlights the higher initial costs of the vehicles and infrastructure compared to petrol / diesel vehicles has a negative impact on publics engaging with the technology (Wu et al 2014), and this was certainly the case in Cornwall, UK. However, more subtle mechanisms behind engaging publics with EV technology not only highlighted the status of the technology as more than a simple consumer product, but highlighted the opportunities within a rural place that can instigate engagement, knowledge mobilisation and consequent implementation. In Cornwall we observed that individuals who were alienated by price concerns can still engage with EVs if they are perceived to be relevant to other aspects of their rural lifestyle and community. Community leadership, i.e. increased familiarity with EVs through communitybased organisation and/or local government use, cultural / personal links and demonstrate benefit, such as improved air quality and a mechanism for increased investment in renewable energy are all factors influencing engagement. In this sense engagement becomes the predecessor to knowledge mobilisation as it is through this initial engagement that individuals then move on to seek and share more knowledge, as well as developing a critical lens on whether knowledges are relevant or reliable to their context.

Additionally, links to other components of forming an intelligent transport system, such as increased renewable energy implementation and investment, can be made more directly. Through recognising the diversity and complexity in a rural region the knowledges around an alternative technology can resonate with the interests, priorities and needs of multiple publics instead of homogenising the interests, priorities and needs in the region. Interestingly the opportunities of new investment are received differently depending on again the specific public within a rural location. In Cornwall, although a narrow peninsula, areas with a thriving tourist economy were more welcoming of the integration to EVs to local transport services. This was very different compared to in-land areas which were dominated by agriculture. The range of EVs and their suitability to travel required distances was raised by publics and local government actors in such areas. Interestingly this was even though the range of many EVs surpass 100 miles per charge, thus rendering this concern largely irrelevant. However, many individuals remained unconvinced and this highlights a knowledge mobilisation gap in this area.

Additionally, other context specific influences, such as willingness to accept 'outsider' investment and a diversification from 'traditional' industry in a region, do often create tension (von Essen and Allen, 2017). However, these tensions can be mitigated if directly addressed and an inclusive participatory approach is deployed in engagement activities relating to alternative technologies and transitions, such as implementing an intelligent transport system. Interestingly, individualised nuances arose in the case study of Cornwall. One example involved a group of stakeholders from the agriculture sector had, by chance, read about the benefits of an electric bus to the renewable energy storage capabilities of another region. This was a key driver of their interest and instigated their involvement in a local renewable energy network. In this scenario EVs were seen as an exciting solution to high energy prices and reducing the use of carbon intensive energy mixes. Overall, the mitigation of these tensions in this way embed a deeper societal transition into a rural setting, with participation and inclusivity in knowledge mobilisation around technologies becoming commonplace and a societal attribute in future generations (Truffer et al. 2010).

To address the complexities of technologies transitions in heterogenous rural places requires learning from climate change communication literature. Although many of the climate change messages in the public domain are still somewhat generalised, there has been a shift in the past decade away from a homogenous understanding of publics, particularly in rural contexts, and towards the production of more tailored engagement and knowledge mobilisation activities that are easier for diverse publics to assimilate and relate to (Thorstensen et al. 2016). This has been done using an array of skill sets and tools, from info-graphics, town and/or village fairs, computer games to entrepreneurial networks (Harshaw and Sheppard, 2013; Kaesehage et al. 2017). The formation of a local renewable energy network, mentioned above, illustrates how a network of individuals with aligned interests can facilitate another technology transition. This observation certainly chimes with insights from the climate change communication literature, where climate 
knoweldges are often built on 'other' relatable knowledges e.g. weather events. Essentially, the benefit of a technology and it's ebenfits are made more relevant through being part of a network but this is dependent on contexts and the individuals that are active in those contexts.

Much like the current EV literature, climate change communication messages have previously focused on relatively 'clichéd' impacts and generalised scientific knowledges, such as melting ice caps, sea-level rise and global temperature rise. Although individuals were (and are) often moved by these messages (especially if accompanied by imagery such as the stranded polar bear), many still struggle to see how climate change will influence their own day-to-day lives and routines (O'Neill et al. 2014). The utilisation of graphic design and participatory approaches has contributed to the production of outputs where these generalised impacts are translated into the context of more familiar, local settings such as communities, homes and gardens; creating a zoom effect. In doing so, these visualisations help to form causal links in the minds of individuals, and can become a trigger when re-exposed to the generalised impacts presented by other communicators (Lorenz et al. 2015). The significance of forming these causal links in people's minds has been studied in scenarios where verbal discussions of climate change and impacts on energy have taken place (Simock et al. 2014). Unfortunately, this sophistication of thought and willingness to collaborate seems to be missing from EV research at present, even though EV knowledges could contribute to wider discourses on climate change mitigation approaches through the creation of intelligent transport systems.

The importance of such sophistication in engagement and recognition of heterogeneity becomes more important in rural settings as individuals, both in the literature and field study, demonstrate better consolidated loyalty to systems that benefit local contexts (Ryglova et al. 2018). Yet, this insight should not be viewed a panacea to the uptake of EVs as loyalty to a local context can be influenced by a range of factors beyond an individual's self-made choice. Rural living can contribute to these influences based on climate, topography and longer average distances of travel if we directly consider transport technologies. As discussed, many stakeholders in Cornwall still showed concern around EVs replacing petrol / diesel vehicles. Essentially, they dismissed the suitability of EVs to their lifestyle even though they actually would have been able to meet their transport needs.

Thus, in such locations the impacts of rurality can influence misconceptions around the suitability of an alternative technology and loyalty is shown towards the existing technology, i.e. petrol / diesel vehicles. These influences prevail even if the misconceptions about a new technology are perceived and deviate from the reality of a technology (Wynne, 2006). Hence, these misconceptions are key areas knowledge mobilisation should prioritise and this is defined by the specific perceptions that are prevalent amongst certain publics, e.g. the agriculture community in Cornwall, UK. In such scenarios the suitability of a technology and realistic approaches to manage the technology's efficacy in a region becomes a fundamental aspect of engagement, knowledge mobilisation and implementation (Latour and Weibel, 2005). During the study, alongside anxieties around range, the suitability of electric batteries to warmer and wetter climates were questioned. These are examples of geographic-led nuances that need to be considered and directly addressed if the development of an intelligent transport system is to be successfully adopted. Importantly the exact manner in which these nuances manifest will vary within a particular rural context as well as from one rural setting to another (Barr, 2011).

\section{Conclusion}

This paper demonstrates the complexity of rural living vis a vis the adoption of EV technology and illustrates the varied mechanisms of how publics construct their perspectives relating to alternative technologies. This presents a complex challenge to scoping and implementing intelligent transport systems, and calls for more sophisticated, in-depth insights to be developed around rural living and its interrelation to alternative technologies. This highlights the key conclusion of this paper that more in-depth case-study qualitative research is required on how tech-transition knowledge is communicated and mobilised in a rural context. The in-depth and reflexive methods to understanding the Cornish context presented in this paper clearly show the benefits this approach could bring to other rural contexts by increasing dialogue around 
the related benefits of technologies, such as EVs. Improved knowledge mobilisation could be achieved through the use of action-based research; a technique used to observe real life settings before designing, planning and evaluating interventions introduced into these settings in collaboration with those who are likely to be affected by the intervention in question (Sheppard, 2012). Through this process, novel EV-related engagement and knowledge mobilisation can be collaboratively designed and tailored to the contexts, needs and interests of publics in a range of different geographic areas. Their effectiveness could be gauged through longitudinal research conducted as part of the action-based research process. This would draw on a mix of ethnographic, survey and/or interview-based methods before, during and after the design, production, refining and implementation of the communication (McNiff, 2013; Stringer, 2013).

This type of action research process is extremely flexible (a necessity for understanding heterogeneity) and could be applied to new arts-based collaborations (e.g. involving drama, graphics, an art exhibition) that could be forged with the aim of producing interactive and/or contextually-relevant communications about the latest research on the environmental and human health impacts of EVs. These collaborations could be established across a range of locations, with residents invited to take part in interviews, surveys, focus groups and/or workshops throughout to monitor and examine any resulting shifts in their EV-related knowledges. Efforts could be made to reach those involved in the design of the communication as well as residents who had not been involved, in order to gauge the wider 'spillover' impacts of such an initiative taking place in particular locations. This could, for example, provide insights into the role of word of mouth messages and knowledge through association (Wood et al, 2016). Knowledge association was particularly strong in this case study as Cornwall has a strong sense of cultural identity. This lends itself to increased involvement through framing the area as 'pioneer'. In this sense, the strong cultural identity expressed by certain publics can influence the acceptance of an alternative technology to demonstrate a progressive community (Brinkman and Hirsh, 2017). Tapping into the cultural identity of a rural area in this way becomes an important driver for aligning the benefits of a sociotechnical transition to the extant perceptions and motivations of specific groups. In this case, individuals became interested and look for opportunities in alternative technologies when a transition is made relevant to them (Chilvers and Longhurst, 2016). Further, the transition has to be culturally credible to the unique elements of their rural lifestyle compared to other places.

The implementation of a sophisticated engagement and knowledge mobilisation effort would be a long-term commitment, with actors encouraged to deliberate with each other, in the hope that discussions would eventually lead to the evolution of organic solutions. To achieve a sociotechnical transition will require a large organised effort with committed personnel. The Climate Outreach model could be an appropriate network to learn from, particularly in a UKcontext. Climate Outreach hold a platform for interactions between a wide range of actors, including academics, policy-makers, media and community groups - public run and NGOs (Climate Outreach, 2014). Since Climate Outreach is connected to a range of individuals within these broad actor groups, they are in a valuable position to catalyse dialogue between these individuals and diverse publics in specific locations. This could be organised in the context of a series of in-depth rural case studies, creating platforms for interaction and dialogue about the different aspects of intelligent transport systems (including specific technologies such as EVs) between diverse actors within these settings.

Overall, the approaches presented in this paper offer a possible way forward for further research into sociotechnical transitions in rural contexts. Future work needs to be responsive to the heterogeneity of rurality and needs to explore ways of producing self-sustaining engagement in knowledge mobilisation and implementation. The exact manner in which the self-sustaining engagement and knowledge mobilisation manifests itself will differ from one rural context to another. Hence, reflexivity is a key practice to ensuring that a transition to an alternative technology can best align with heterogeneous forms of rural living. 
[1] Axsen, J. \& Kurani, K. S. (2012). Who can recharge a plug-in electric vehicle at home? Transportation Research Part D: Transport and Environment, 17(5): 349-355. DOI: 10.1016/j.trd.2012.03.001.

[2] Barr, S. (2011). Climate Forums: virtual discourses on climate change and the sustainable lifestyle. Area, 43(1): 14-22. DOI: 10.1111/j.1475-4762.2010.00958.x.

[3] Barre, A., Suarda, F., Gérard, M., Montaru, M. \& Riu, D. (2013) Statistical analysis for understanding and predicting battery degradations in real-life electric vehicle use. Journal of Power Sources, 245: 886-856. DOI: 10.1016/j.jpowsour.2013.07.052.

[4] Brinkman, J. \& Hirsh, R. (2017). Welcoming Wind Turbines and the PIMBY ("Please in My Backyard") Phenomenon: The Culture of the Machine in the Rural American Midwest. Technology and Culture, 58(2), 335-367.

[5] Brulle, R. J., Carmichael, J. \& Jenkins, J. C. (2012). Shifting public opinion on climate change: an empirical assessment of factors influencing concern over climate change in the U.S., 2002 - 2010. Climatic Change, 114(2): 169-188. DOI: 10.1007/s10584-012-0403-y.

[6] Bunce, L., Harris, M. \& Burgess, M. (2014). Charge up then charge out? Drivers' perceptions and experiences of electric vehicles in the UK. Transportation Research Part A: Policy and Practice, 59: 278-287. DOI: 10.1016/j.tra.2013.12.001.

[7] Chilvers, J. \& Longhurst, N. (2016). Participation in Transition(s): Reconceiving Public Engagements in Energy Transitions as Co-Produced, Emergent and Diverse. Journal of Environmental Policy \& Planning, 18(5), 585-607. DOI: 10.1080/1523908X.2015.1110483.

[8] Cotton, M. \& Devine-Wright, P. (2012). Making electricity networks 'visible': industry actor constructions of 'publics' and public engagement in infrastructure planning. Public Understanding of Science, 21(1), 17-35. DOI: 10.1177/0963662510362658.

[9] Docherty, I., Marsden, G. \& Anable, J. (2018). The governance of smart mobility. Transportation Research Part A: Policy and Practice, 115, 114-125. DOI: 10.1016/j.tra.2017.09.012.

[10] Egbue, O. \& Long, S. (2012). Barriers to widespread adoption of electric vehicles: An analysis of consumer attitudes and perceptions. Energy Policy, 48: 717-729. DOI: 10.1016/j.enpol.2012.06.009.

[11] Elo, S. \& Kyngas, H. (2008). The qualitative content analysis process. The Journal of Advanced Nursing 62(1): 107-115. DOI: 10.1111/j.1365-2648.2007.04569.x.

[12] Esmene, S., Taylor, T. \& Leyshon, M. (2017). Knowledge, experience and the circus: academic perspectives on the processes of communicating the environmental and health impacts of electric vehicles. Local Environment, 22(6), 651-666. DOI: $10.1080 / 13549839.2016 .1250736$.

[13] Gamble, J., Muggleston, S., Hedderley, D., Parminter, T. \& Richardson-Harman, N. (2000). Genetic engineering: The public's point of view. Report to Stakeholders. [research report]. Auckland: Horticulture and Food Research Institute of New Zealand Limited.

[14] Gray, D., Farrington, J., Shaw, J., Martin, S. \& Roberts, D. (2001). Car dependence in rural Scotland: transport policy, devolution and the impact of the fuel duty escalator. Journal of Rural Studies 17(1): 113-135. DOI: 10.1016/S0743-0167(00)00035-8.

[15] Harshaw, H. W. \& Sheppard, S. R. J. (2013). Using the recreation opportunity spectrum to evaluate the temporal impacts of timber harvesting on outdoor recreation settings. Journal of Outdoor Recreation and Tourism, 1-2: 40-50. DOI: 10.1016/j.jort.2013.03.001.

[16] Hermwille, L. (2016). The role of narratives in socio-technical transitions-Fukushima and the energy regimes of Japan, Germany, and the United Kingdom. Energy Research \& Social Science, 11, 237-246. DOI: 10.1016/j.erss.2015.11.001. 
[17] Holland, S., Mansur, E., Muller, N. \& Yates, A. (2016). Are There Environmental Benefits from Driving Electric Vehicles? The Importance of Local Factors. American Economic Review. 106(12), 3700-3729. DOI: 10.1257/aer.20150897.

[18] Kaesehage, K., Leyshon M., Ferns ,G. \& Leyshon, C. (2017). Seriously Personal: the Reasons that Motivate Entrepreneurs to Address Climate Change. Journal of Business Ethics, 157(4), 1091-1109. DOI: 10.1007/s10551-017-3624-1.

[19] Jad'ud’ová, J., Marková, I., Vicianová, J., Bohers, A. \& Murin, I. (2018). Study of Consumer Preferences of Regional Labeling. Slovak Case Study. European Countryside, 10(3), 429441. DOI: 10.2478/euco-2018-0024.

[20] Larson, P. D., Viafara, J., Parsons, R. V., \& Elias, A. (2014). Consumer attitudes about electric cars: Pricing analysis and policy implications. Transportation Research Part A: Policy and Practice, 69: 299-314. DOI: 10.1016/j.tra.2014.09.002.

[21] Latour, B. \& Weibel, P. (2005). Making Things Public: Atmospheres of Democracy. Cambridge, MS: MIT Press.

[22] Mathiesen, B., Lund, H., Connolly, D., Wenzel, H., Østergaard, P., Möller, B., Nielsen, S., Ridjan, I., Karnøe, P., Sperling, K. \& Hvelplund, F. (2015). Smart Energy Systems for coherent $100 \%$ renewable energy and transport solutions. Applied Energy, 145, pp. 139154. DOI: 10.1016/j.apenergy.2015.01.075.

[23] Newman, D., Wells, P., Donovan, C., Nieuwenhuis, P. \& Davies, H. (2014). Urban, sub-urban or rural: where is the best place for electric vehicles? International Journal of Automotive Technology and Management, 14(4), 306. DOI: 10.1504/IJATM.2014.065295.

[24] O'Neill, S. J. \& Smith, N. (2014). Climate change and visual imagery. WIREs Clim Change 2014, 5: 73-87. DOli: 10.1002/wcc.249.

[25] Peters, A. \& Dutschke, E. (2014). How do Consumers Perceive Electric Vehicles? A Comparison of German Consumer Groups. Journal of Environmental Policy \& Planning, 16(3): 358-377. DOI: 10.1080/1523908X.2013.879037.

[26] Plotz, P., Schneider, U., Globisch, J. \& Dütschke, E. (2014). Who will buy electric vehicles? Identifying early adopters in Germany. Transportation Research Part A: Policy and Practice, 67: 96-109. 10.1016/j.tra.2014.06.006.

[27] Poggi, F., Firmino, A. \& Amado, M. (2017). SMART RURAL: a model for planning net-zero energy balance at municipal level. Energy Procedia, 122, 56-61. DOI: 10.1016/j.egypro.2017.07.287.

[28] Ryglová, K., Rašovská, I., Šácha, J. \& Maráková, V. (2018). Building Customer Loyalty in Rural Destinations as a Pre-Condition of Sustainable Competitiveness. Sustainability, 10(4), 957. DOI: 10.3390/su10040957.

[29] Schot, J., Kanger, L. \& Verbong, G. (2016). The roles of users in shaping transitions to new energy systems. Nature Energy 1(5), 16054. DOI: 10.1038/nenergy.2016.54.

[30] Simock, N., MacGregor, S., Catney, P., Dobson, A., Ormerod, M., Robinson, Z., Ross, S., Royston, S. \& Hall, S. M. (2014). Factors influencing perceptions of domestic energy information: content, source and process. Energy Policy, 65: 455-464. DOI: 10.1016/j.enpol.2013.10.038.

[31] Siwach, M. \& Dahiya, A. (2009). Knowledge and Utilization of Consumer Education by Rural and Urban Women. Journal of Human Ecology, 25(1), 41-44. DOI: 10.1080/09709274.2009.11906133.

[32] Thorstensen, E., Forsberg, E., Underthun, A., Danihelka, P. \& Řeháček, J. (2016). Regional Development and Climate Change Adaptation: A Study of the Role of Legitimacy. European Countryside, 8(3) 207-226. DOI: 10.1515/euco-2016-0016.

[33] Tiessen, H., Brklacich, M., Breulmann, G. \& Menezes, R. S. C. (2008). Communicating Global Change Science to Society. Washington, DC: Island Press. 
[34] Truffer, B., Störmer, E., Maurer, M. \& Ruef, A. (2010). Local strategic planning processes and sustainability transitions in infrastructure sectors. Environmental Policy and Governance, 20(4), 258-269. DOI: 10.1002/eet.550.

[35] Von Essen, E. \& Allen, M. (2017). Taking Prejudice Seriously: Burkean Reflections on the Rural Past and Present. Sociologia Ruralis 58(3), 543-561. DOI: 10.1111/soru.12183.

[36] Wolf, J. \& Moser, S. C. (2011). Individual understandings, perceptions, and engagement with climate change: insights from in-depth studies across the world. Wiley Interdisciplinary Reviews: Climate Change, 2(4): 547-569. DOI: 10.1002/wcc.120.

[37] Wood, J., Brown, J., Bond, M. \& Suguri, V. (2016). Older Adult Transportation in Rural Communities: Results of an Agency Survey. Journal of Public Transportation 19(2), 154-167. DOI: 10.5038/2375-0901.19.2.9.

[38] Wu, G., Inderbitzin, A. \& Bening, C. (2015). Total cost of ownership of electric vehicles compared to conventional vehicles: A probabilistic analysis and projection across market segments. Energy Policy, 80, 196-214. DOI: 10.1016/j.enpol.2015.02.004.

[39] Wynne, B. E. (1992). Misunderstood misunderstanding: social identities and public uptake of science. Public Understanding of Science 1(3): 281-304. DOI: 10.1088/0963-6625/1/3/004.

[40] Zhang, L., Brown, T. \& Samuelsen, S. (2013). Evaluation of charging infrastructure requirements and operating costs for plug-in electric vehicles. Journal of Power Sources, 240: 515-524. DOI: 10.1016/j.jpowsour.2013.04.048.

\section{Other sources}

[41] Climate Outreach (2014). Climate Outreach and Information Network: Communicating Climate Change. Available from: http://www.climateoutreach.org.uk/communicating-climatechange/ [Accessed: 18/01/2019].

[42] Cornwall Council (2011). Data and research. Useful facts and figures about Cornwall. Cornwall, UK. Cornwall Council. Available from: http://www.cornwall.gov.uk/default.aspx?page=2035 [Accessed:29/01/2019].

[43] Cornwall Council (2019). Cornwall and the Isles of Scilly Community Profiles. Cornwall Council. Available from: https://cornwall.communityinsight.org/ [Accessed: 18/11/2019].

[44] Department for Transport (2012). The plug-in car grant extended to vans. London, UK. Department for Transport. Available from: http://www.dft.gov.uk/news/press-releases/dftpress-20120117/ [Accessed: 6/02/2019].

[45] Office for National Statistics (2011). The 2011 rural/urban classification. Office of National Statistics, UK. Available from: http://www.ons.gov.uk/ons/guidemethod/geography/products/area-classifications/2011-rural-urban/index.html [Accessed: 20/02/2019].

[46] Office for National Statistics (2012). Population Estimates for UK, England and Wales, Scotland and Northern Ireland, Mid-2011 and Mid-2012. Office of National Statistics, UK. Available from: http://www.ons.gov.uk/ons/rel/pop-estimate/population-estimates-for-uk-england-and-wales--scotland-and-northern-ireland/mid-2011-and-mid-2012/index.html [Accessed: 11/02/2017]. 